\title{
Dynamics of strontium-90 in forest ecosystems
}

\author{
F. Bruchertseifer, M. Steiner, L. Hiersche, B. Savkin, A. Poppitz-Spuhler and E. Wirth' \\ German Federal Office for Radiation Protection, Institute for Radiation Hygiene, \\ Section Radioecology, Ingolstädter Landstrasse 1, 85762 Oberschleissheim, Germany \\ ${ }^{1}$ German Federal Office for Radiation Protection, Institute for Atmospheric Radioactivity. \\ Rosastrasse 9, 79098 Freiburg, Germany
}

\begin{abstract}
The behaviour of $\mathrm{Sr}-90$ in coniferous forest ecosystems was investigated at three different sites in Bavaria, South Germany. In 1995 and 1996 the Sr-90 activity was measured in about 200 samples, covering different soil horizons and understory vegetation. In addition, the Cs-137 activity was measured for comparison. Sr90 mainly originates from the fall-out of the nuclear weapons tests during the 50ies and 60ies, the contribution of the Chemobyl accident being considerably lower. The current distribution of $\mathrm{Sr}-90$ within the ecosystem therefore represents the long-term consequence of the dymamic behaviour during the last three to four decades. The results show that the major portion of Sr-90 in forest soil still persists in the organic horizons, indicating a very low migration rate. The qualitatively different vertical profiles of St-90 and Cs-137 suggest an efficient transfer from soil to plants and a continuous supply of $\mathrm{Sr}-90$ to the litter horizon via leaf-turnover. The activity levels in edible berries were rarely higher than a few $\mathrm{Bq} / \mathrm{kg}$ (dw). $\mathrm{Sr}_{-}-90$ activities between about 10 and $50 \mathrm{~Bq} / \mathrm{kg}$ (dw) were measured in other parts of green plants. The uptake of Cs-137 from soil to plants is significantly higher in forests than in agricultural ecosystems, especially on mineral soils. The differences for Sr-90 are less pronounced than in the case of $\mathrm{Cs}-137$.
\end{abstract}

\section{INTRODUCTION}

During the last decade the dynamics of radiocaesium in forest ecosystems has been investigated intensively. Data on the distribution and the transfer of Sr-90 within forests, however, are rare. It was estimated that an activity level of about $970 \mathrm{~Bq} / \mathrm{m}^{2}$ in 1996 originates from the atmospheric nuclear weapons tests during the 50ies and 60ies [1]. The contribution of Sr-90 from the Chemobyl accident, about $150 \mathrm{~Bq} / \mathrm{m}^{2}$ in 1996 in the region around Munich, is considerably smaller [2]. Accordingly, the present distribution of Sr-90 in forest ecosystems is expected to represent mainly the long-term consequence of the dynamic behaviour of St-90 during the last three to four decades.

Activity levels of Sr-90 were measured in about 200 samples of different soil horizons and understory vegetation to investigate the behaviour of $\mathrm{Sr}-90$ in three coniferous forests in South Germany. In addition, the activity levels of $\mathrm{Cs}-137$ were determined for comparison.

\section{MATERIALS AND METHODS}

Three different coniferous forests located in Bavaria, Germany, were investigated. The sampling sites can be characterised as follows:

- Hochstadt: $\quad$ Pure Norway spruce (Picea abies) stand, age about 100 years. The soil type is cambisol on calcareous moraine. The thicknesses of the soil horizons were: $\mathrm{O}_{1} 0.6 \mathrm{~cm}, \mathrm{O}_{\mathrm{f}} 3.1 \mathrm{~cm}, \mathrm{O}_{\mathrm{h}} 2.2 \mathrm{~cm}, \mathrm{~A} 2.1 \mathrm{~cm}$ and $\mathrm{B} 8.3 \mathrm{~cm}$.

- Siegenburg: Scots pine (Pinus sylvestris, about $90 \%$ of the stand) and Norway spruce (Picea abies, about $10 \%$ of the stand), age about 120 years. The soil type is podsol on nutrient-poor dune sand. The thicknesses of the soil horizons were: $O_{1} 0.9 \mathrm{~cm}$, $O_{\mathrm{f}} 1.7 \mathrm{~cm}, \mathrm{O}_{\mathrm{h}} 2.1 \mathrm{~cm}, \mathrm{~A} 1.8 \mathrm{~cm}$ and $\mathrm{B} 10.0 \mathrm{~cm}$. 
- Garching/Alz: Scots pine (Pinus sylvestris, about $30 \%$ of the stand) and Norway spruce (Picea abies, about $70 \%$ of the stand), age about 120 years. The soil type is pararendsina on calcareous gravel. The thicknesses of the soil horizons were: $\mathrm{O}_{1} 0.7 \mathrm{~cm}$, $\mathrm{O}_{\mathrm{f}} 0.7 \mathrm{~cm}, \mathrm{O}_{\mathrm{h}} 1.8 \mathrm{~cm}, \mathrm{~A} 4.2 \mathrm{~cm}$ and $\mathrm{B} 8.6 \mathrm{~cm}$.

At each sampling site the soil is characterised by the typical horizontation of an undisturbed forest floor (see Fig. 1).

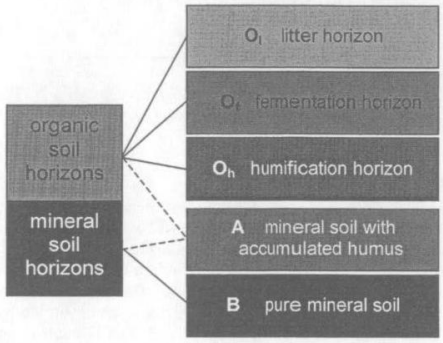

Figure 1: Natural horizontation of undisturbed forest soil at the Bavarian forest sites investigated.

In 1995 and 1996 about 200 samples of different soil horizons and green plants were collected. For each site nine soil profiles were taken according to the natural horizontation at the three forest sites investigated.

All samples were air-dried and ground. The plant samples were pooled for further preparation. The Sr-90 activity was measured using a proportional counting system after radiochemical separation via the nitric method. The Cs-137 activity was measured before using high purity germanium detectors.

\section{RESULTS AND DISCUSSION}

\subsection{Activity levels in soil}

The total Sr-90 inventory of the soil horizons investigated $\left(\mathrm{O}_{l}, \mathrm{O}_{f}, \mathrm{O}_{\mathrm{h}}, \mathrm{A}\right.$, and the top $10 \mathrm{~cm}$ of $\left.\mathrm{B}\right)$ is 460 $\mathrm{Bq} / \mathrm{m}^{2}, 220 \mathrm{~Bq} / \mathrm{m}^{2}$, and $650 \mathrm{~Bq} / \mathrm{m}^{2}$ for the sites Hochstadt, Siegenburg, and Garching/Alz, respectively. The corresponding coefficients of variation are $49 \%, 57 \%$, and $61 \%$. The total deposition is estimated to be around $1100 \mathrm{~Bq} / \mathrm{m}^{2}$ at sampling time, with contributions of about $970 \mathrm{~Bq} / \mathrm{m}^{2}$ and about $150 \mathrm{~Bq} / \mathrm{m}^{2}$ originating from the nuclear weapons fallout and the Chernobyl accident, respectively. Up to about $60 \%$ of the total deposition of $\mathrm{Sr}-90$ is still located in the soil horizons investigated. The migration of $\mathrm{Sr}-90$ to deeper soil horizons is very slow.

The activity level of $\mathrm{Sr}-90$ in soil is inhomogeneously distributed in the analysed soil horizons. More than $85 \%$ still persists in the organic horizons $\mathrm{O}_{1}, \mathrm{O}_{\mathrm{f}}$, and $\mathrm{O}_{\mathrm{h}}$, and less than $15 \%$ is located in the $A$ horizon and the top $10 \mathrm{~cm}$ of the $\mathrm{B}$ horizon. Specific activities of different horizons are depicted in Fig. 2. For each horizon activity levels were calculated as geometric means of nine profiles, assuming a lognormal spatial distribution of Sr-90 in forest soil. Activity levels of $\mathrm{Sr}-90$ in the $\mathrm{O}_{\mathrm{f}}$ and $\mathrm{O}_{\mathrm{h}}$ horizons range typically between 16 and $30 \mathrm{~Bq} / \mathrm{kg}(\mathrm{dw})$. The highest specific activity of $57 \mathrm{~Bq} / \mathrm{kg}(\mathrm{dw})$ was detected in the $\mathrm{O}_{\downarrow}$ horizon at Garching/Alz. The coefficients of variation for specific soil horizons and sampling sites amount up to $30 \%$ for $\mathrm{Sr}-90$.

Activity concentrations of $\mathrm{Cs}-137$ in different horizons of forest soil are also shown in Fig. 2 for comparison. The coefficients of variation for specific soil horizons and sampling sites range up to $50 \%$ 
for Cs-137, and even exceed this value in a few cases. The spatial variability of Cs-137 is higher than that of $\mathrm{Sr}-90$. Similar to $\mathrm{Sr}-90$, the dominant portion of $\mathrm{Cs}-137$ in the soil profiles investigated, more than $70 \%$, is located in the organic horizons $\mathrm{O}_{b}, \mathrm{O}_{f}$, and $\mathrm{O}_{\mathrm{h}}$. The vertical profiles are qualitatively different for $\mathrm{Sr}-90$ and $\mathrm{Cs}-137$, especially with respect to the $\mathrm{O}_{1}$ horizon. The specific activity of $\mathrm{Sr}-90$ in the $\mathrm{O}_{1}$ horizon is higher than or comparable with that in the $\mathrm{O}_{\mathrm{f}}$ horizon. The specific activity of Cs-137 in the $\mathrm{O}_{1}$ horizon is less than a third of that in the Or horizon.
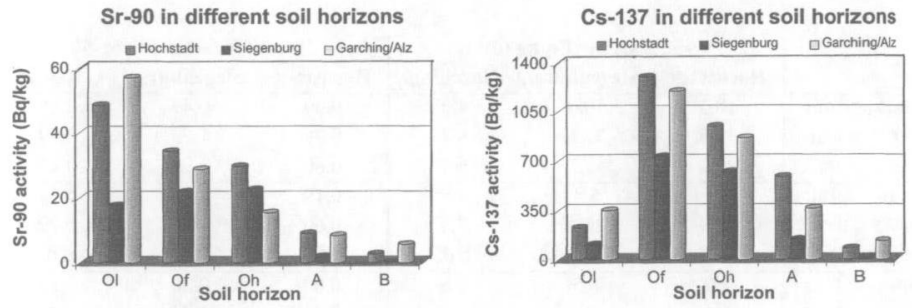

Figure 2: Specific activities of Sr-90 and Cs-137 in soil horizons at the Bavarian forest sites investigated.

These findings lead to the conclusion that the dynamic behaviour of $\mathrm{Sr}-90$ and Cs-137 is governed by different mechanisms. As described in detail in [4], the slow migration of Cs-137 in forest soil is mainly due to an upward transport mediated by fungal mycelia. The concentration of strontium in fungal fruit bodies is lower than that of caesium [5]. It is therefore reasonable to assume that the activity level of Sr90 in fungal mycelia is lower than that of Cs-137. As a consequence, upward transport mediated by fungal mycelia is expected to be less important for $\mathrm{Sr}-90$. A completely different mechanism is proposed to explain the surprisingly high specific activity of $\mathrm{Sr}-90$ in the uppermost $\mathrm{O}_{1}$ horizon and the slow migration in forest soil. We speculate that an efficient transfer from soil to plants and a continuous supply of $\mathrm{Sr}-90$ to the litter horizon via leaf-turnover governs the dynamic behaviour of Sr-90 in forest ecosystems.

\subsection{Activity levels in plants and transfer soil to plant}

The specific activities of Sr-90 in pooled samples of blackberry (Rubus fruticosus), raspberry (Rubus idaeus), and bilberry (Vaccinium myrtillus) amount up to $50 \mathrm{~Bq} / \mathrm{kg}$ (dw). The activity levels of Sr-90 show a common trend for all sampling sites and species investigated, with lowest values for fruit (see Table 1). In most cases the specific activity in leaves and stalks is a factor of 3 and more higher than in berries. These differences in activity levels are less pronounced for different parts of blackberry and raspberry at Garching/Alz. Activity levels of Sr-90 in the green plants investigated are up to 15 times higher than in agricultural products originating from the same region [3].

Transfer factors (concentration ratios) defined as

$$
T F=\frac{{ }^{90} S r_{\text {ptant }}}{{ }^{00} S r_{\text {organic soil }}}
$$

were calculated to quantify the transfer of $\mathrm{Sr}-90$ from soil to plants. Here ${ }^{90} \mathrm{Sr}_{\text {plant }}$ and ${ }^{90} \mathrm{Sr}_{\text {organic soils }}$ expressed as $\mathrm{Bq} / \mathrm{kg}(\mathrm{dw})$, denote the specific activities of understory vegetation and the organic horizons, 
respectively. The average specific activity of the organic horizons $\mathrm{O}_{l}, \mathrm{O}_{f}$ and $\mathrm{O}_{h}$ was calculated from the specific activities and the mass per area of the different soil horizons.

Table 1: Specific activities and transfer factors of $\mathrm{Sr}-90$ for understory vegetation at the Bavarian forest sites investigated.

\begin{tabular}{ll|ccc|ccc} 
& & \multicolumn{2}{|c}{ Sr-90 activity (Bq/kg (dw)) } & \multicolumn{3}{c}{ Transfer factor for Sr-90 } \\
& & Hochstadt & Siegenburg & Garching & Hochstadt & Siegenburg & Garching \\
\hline black- & fruit & 10.3 & 10.6 & 4.0 & 0.30 & 0.49 & 0.15 \\
berry & leaf & 32.8 & 37.1 & 8.4 & 0.96 & 1.73 & 0.30 \\
& stalk & 27.2 & 41.2 & 6.4 & 0.80 & 1.93 & 0.23 \\
\hline rasp- & fruit & 6.4 & 5.4 & 6.5 & 0.19 & 0.25 & 0.24 \\
berry & leaf & 20.4 & 26.3 & 7.8 & 0.60 & 1.23 & 0.29 \\
& stalk & 27.7 & 35.3 & n.d. & 0.81 & 1.65 & n.d. \\
\hline bil- & fruit & 2.7 & 6.5 & 2.8 & 0.08 & 0.30 & 0.10 \\
berry & leaf & 9.1 & 37.3 & 11.9 & 0.27 & 1.74 & 0.44 \\
& stalk & 10.8 & 49.6 & 20.2 & 0.32 & 2.32 & 0.74
\end{tabular}

The transfer of Sr-90 from soil to green plants is highest for the forest site on nutrient-poor dune sand (Siegenburg). Transfer factors for $\mathrm{Sr}-90$ are considerably lower for the two other sampling sites on calcareous parent material (Hochstadt and Garching/Alz). At each sampling site the transfer factors for Sr-90 are significantly higher than the corresponding values for Cs-137, except for bilberry [6]. The comparably high transfer from soil to green plants supports the hypothesis that a continuous and effective cycling of Sr-90 due to falling needles and leaves may exist in forest ecosystems.

\section{SUMMARY}

Up to about $60 \%$ of the total deposition of $\mathrm{Sr}-90$ can still be found in the investigated soil horizons. The dominant portions of $\mathrm{Sr}-90$ and $\mathrm{Cs}-137$ are located in the organic horizons $\mathrm{O}_{\mathrm{l}}, \mathrm{O}_{\mathrm{f}}$, and $\mathrm{O}_{\mathrm{h}}$, indicating that the net downward migration is slow for both $\mathrm{Sr}-90$ and $\mathrm{Cs}-137$.

The vertical profiles for Sr-90 and Cs-137 are qualitatively different with respect to the $\mathrm{O}_{1}$ horizon. For Sr-90 the specific activity of the $O_{1}$ horizon is higher than or comparable with that of the $O_{f}$ horizon. For Cs-137, however, the specific activity is less than a third of that of the $O_{f}$ horizon.

Activity concentrations of $\mathrm{Sr}-90$ in understory vegetation are up to 15 times higher than in agricultural products originating from the same region, the transfer being the highest for the forest site on nutrientpoor dune sand. Furthermore, the transfer of $\mathrm{Sr}_{-}-90$ from forest soil to green plants is generally higher than the transfer of Cs-137. Activity levels of Sr-90 show a common trend for all sampling sites and species investigated, with lowest values for berries.

Our results indicate an efficient transfer from soil to plants and a continuous supply of $\mathrm{Sr}-90$ to the litter borizon via leaf-turnover. This process appears to be less significant for Cs-137, where the slow migration in forest soil is mainly due to an upward transport mediated by fungal mycelia.

\section{Acknowledgements}

The authors would like to thank Mr. Rolf Krestel for his indispensable help during soil sampling. 


\section{References}

[1] United Nations Scientific Committee on the Effects of Atomic Radiation (UNSCEAR) 2000, Report to the General Assembly

[2] Hötzl H., Rosner G., and Winkler R., "Ground depositions and air concentrations of Chennobyl fallout radionuclides at Munich-Neuherber", Radiochimica Acta, 41 (1987), 181-190.

[3] Umweltradioaktivität und Strahlenbelastung, Report 1999 - Ministry of Environment, Nature Conservation and Reactor Safety, German Federal Republic, Bonn, 2000.

[4] Rafferty B., Brennan M., Dawson D., and Dowding D., "Mechanisms of Cs-137-migration in coniferous forest soils", Journal of Environmental Radioactivity, 48 (2000), 131-148.

[5] Yoshida S., and Muramatsu Y., "Concentration of alkali and alkaline earth elements in mushrooms and plants collected in Japanese pine forest", and their relationship with Cs-137, Journal of Environmental Radioactivity, 41 (1998), 183-205, and references therein.

[6] Long-term dynamics of radionuclides in semi-natural environments: derivation of parameters and modelling, final report of the research project SEMINAT (EC research contract FI4P-CT95-0022), Rome, 2000. 